\title{
A COMPARATIVE STUDY OF EPIDURAL BUPIVACAINE AND EPIDURAL BUPIVACAINE WITH LOW- DOSE BUTORPHANOL FOR PERIOPERATIVE ANALGESIA IN PATIENTS UNDERGOING ELECTIVE GYNAECOLOGICAL SURGERIES
}

\author{
Subhrajyoti Chattopadhyay', Susanta Sarkar², Mohanchandra Mandal ${ }^{3}$, Sumit Chakrabarti ${ }^{4}$ \\ ${ }^{1}$ Associate Professor, Department of Anaesthesiology, North Bengal Medical College, Sushrutanagar, Darjeeling, West Bengal. \\ ${ }^{2}$ Associate Professor, Department of Anaesthesiology, North Bengal Medical College, Sushrutanagar, Darjeeling, West Bengal. \\ ${ }^{3}$ Associate Professor, Department of Anaesthesiology, North Bengal Medical College, Sushrutanagar, Darjeeling, West Bengal. \\ ${ }^{4}$ Consultant Obstetrician and Gynaecologist, Siliguri, West Bengal.
}

\section{ABSTRACT}

\section{BACKGROUND}

Epidural anaesthesia with bupivacaine is a popular method of anaesthesia for gynaecological surgery. Several studies have alr eady reported that opioids as neuraxial additive markedly prolonged the postoperative analgesic effect of local anaesthetics without much increase of adverse events. Sixty adult females of ASA physical status I and II, aged between 20 - 60 years, scheduled for elective gynaecological surgery were included in this randomised double-blind controlled study.

Aim of this study was to compare the efficacy of low-dose butorphanol as additive to epidural bupivacaine and epidural bupivacaine alone for perioperative analgesia.

\section{MATERIALS AND METHODS}

The patients were randomly allocated into two equal groups to receive either $15-20 \mathrm{~mL}$ of $0.5 \%$ bupivacaine hydrochloride (Group I, $\mathrm{n}=30$ ) or $15-20 \mathrm{~mL}$ of $0.5 \%$ bupivacaine hydrochloride plus low-dose ( $0.5 \mathrm{~mL}$ ) butorphanol tartrate (Group II, $\mathrm{n}=30$ ) according to computerised randomised table. The dose of $0.5 \%$ bupivacaine hydrochloride was calculated according to the height of the patient (i.e. $150-160 \mathrm{~cm}$ : $15 \mathrm{~mL}$ and $160 \mathrm{~cm}$ onwards: $20 \mathrm{~mL}$ ). Under all aseptic precautions, epidural anaesthesia was given with 18G Tuohy needle in sitting posture at $\mathrm{L}_{2-3}$ or $\mathrm{L}_{3-4}$ interspace using loss of resistance technique to identify epidural space. After negative aspiration test, the study drug was slowly injected as per protocol. No other analgesic was given to the patients intraoperatively. Onsets of sensory and motor block were assessed. Duration of sensory and motor block, height of block and duration of analgesia also were assessed. Time to first rescue analgesic was taken as the duration of analgesia; VAS and VRS scores at that point were also noted. The total number of doses of rescue analgesics required in first 24 hours was also noted. Blood pressure, heart rate and respiratory rate were recorded at stipulated intervals. Adverse events, if any were also noted. The data was analysed using appropriate statistical test.

\section{RESULTS}

The onset and duration of sensory and motor blocks were comparable between the two groups. Duration of analgesia was significantly longer in patients receiving butorphanol additive group. Vital parameters were well maintained during intraoperative and postoperative period in both the groups. A few minor adverse events such as nausea, vomiting, pruritus and shivering were found in both the groups, but no significant difference on analysis.

\section{CONCLUSION}

A single low-dose $(0.5 \mathrm{mg})$ butorphanol along with epidural bupivacaine $(0.5 \%)$ administration prolongs the duration of effective analgesia compared with bupivacaine $(0.5 \%)$ alone. This low-dose $(0.5 \mathrm{mg})$ butorphanol as additive does not appear to influence the speed of onset of blocks. Haemodynamic parameters and adverse events are also not influenced.

\section{KEYWORDS}

Anaesthesia, Analgesia, Bupivacaine, Butorphanol, Epidural, Fentanyl, Pain, Sedation.

HOW TO CITE THIS ARTICLE: Chattopadhyay S, Sarkar S, Mandal M, et al. A comparative study of epidural bupivacaine and epidural bupivacaine with low-dose butorphanol for perioperative analgesia in patients undergoing elective gynaecological surgeries. J. Evolution Med. Dent. Sci. 2017;6(24):1985-1991, DOI: 10.14260/Jemds/2017/435

\section{BACKGROUND}

Pain is an unpleasant sensory and emotional experience associated with actual or potential tissue damage or described in terms of such damage. ${ }^{1}$

Financial or Other, Competing Interest: None.

Submission 13-02-2017, Peer Review 08-03-2017,

Acceptance 15-03-2017, Published 23-03-2017.

Corresponding Author:

Dr. Subhrajyoti Chattopadhyay,

C/o. Mr. Satyajit Chakroborty,

Trinayani Apartment, $2^{\text {nd }}$ Floor,

Taltala Arabinda Pally,

Siliguri-734006, West Bengal.

E-mail:drsubhra1972@gmail.com

DOI: $10.14260 /$ jemds $/ 2017 / 435$
Surgical trauma causes tissue damage with consequent release of algesic substances such as prostaglandins, histamine, serotonin and bradykinins. This stress response is mediated by hypothalamo-pituitary-adrenal and sympathoadrenal interactions. If uncontrolled, pain continues in the postoperative period. Unresolved pain increases myocardial $\mathrm{O}_{2}$ demand and risk of pulmonary complications. Also it may precipitate venous stasis and platelet aggregations resulting in deep vein thrombosis. ${ }^{2,3}$

Epidural anaesthesia is now frequently used for gynaecological surgery owing to its favourable effects on several aspects of operative outcome such as reduced intraoperative blood loss, minimal stress response to surgery, decreased postoperative catabolism, decreased incidences of postoperative nausea and vomiting, reduced incidences of 
thromboembolic events and improved postoperative pulmonary function. ${ }^{2-4}$ Epidural analgesia provide better analgesia, which may not be achieved with parenteral opioids owing to their innate adverse effects. ${ }^{5}$ Moreover, it can be utilised to extend analgesia into postoperative period.

Bupivacaine is a commonly used agent for epidural anaesthesia for its long duration of action. Adjunctive agents (Opioids and alpha- 2 agonists) added to local anaesthetics via epidural and intrathecal routes are reported to improve the quality of analgesia and to increase the duration of analgesia and may provide a dose sparing effect. ${ }^{6}$ Epidural administration of opioids as additive to bupivacaine for postsurgical pain relief have resulted in better pain scores. Several authors have suggested that this combination may produce a synergistic effect, while reducing the incidence of adverse events.5,6 Butorphanol, (a partial mu-opioid receptor antagonist and kappa-opioid receptor agonist) cause minimum respiratory depression. The use of low-dose butorphanol with epidural bupivacaine is recently reported sporadically to produce earlier onset, longer duration and better quality of analgesia compared with bupivacaine dose. ${ }^{7}$ With this idea keeping in mind, the present study was designed to compare between low-dose butorphanol as adjuvant to epidural bupivacaine and epidural bupivacaine alone in patients undergoing elective gynaecological surgeries in respect of block characteristics, haemodynamic parameters and adverse events if any.

\section{Aims of this Study were to Evaluate}

- The onset, duration and height of sensory analgesia between the study groups.

- The onset and duration of motor blockade between the study groups.

- $\quad$ To assess adverse effects of these drugs (if any).

\section{MATERIALS AND METHODS}

After the approval from the West Bengal University of Health Sciences (WBUHS) and the Institute's Ethics Committee, this randomised parallel-group, double-blind controlled study (Thesis Work) was carried out under the Department of Anaesthesiology of the Institute.

Sixty females of aged 20 - 60 years, conforming to ASA physical status I and II, posted for elective gynaecological surgery (abdominal hysterectomy, vaginal hysterectomy, vaginal hysterectomy with pelvic floor repair) were included in this study. Exclusion criteria were any local infection in the lumbar region, known hypersensitivity to amide local anaesthetics, bleeding diathesis, spinal deformity and presence of preexisting cardiac, renal, neurological or psychiatric disorder. Patients with diabetes mellitus or other metabolic diseases were also excluded.

Patients were visited on the preoperative day for preanaesthetic checkup. Detailed history of present illness, any relevant past history of disease was recorded. Clinical examination of respiratory system, cardiovascular system and central nervous system was done. Vertebral spine was also examined. Relevant laboratory investigations were noted. The patients who fulfilled the above inclusion criteria and had none of the exclusion criteria mentioned above were explained about the study. The patients were explained in detail about the procedure of lumbar epidural block. All their queries and doubts were answered to get their confidence and support. Written informed consent was obtained.
Patients were kept fasting overnight after a light meal. All patients received Tab. diazepam $10 \mathrm{mg}$ orally in the night before surgery. Inj. metoclopramide $10 \mathrm{mg}$ and Inj. ranitidine $50 \mathrm{mg}$ slow IV were given 1 to 2 hours before operation. Thus selected and enlisted for the study, patients were randomly allocated into two groups using a computer generated randomisation chart. The patients received either $15-20 \mathrm{~mL}$ of $0.5 \%$ bupivacaine hydrochloride (Group I, $\mathrm{n}=30$ ) or 15 $20 \mathrm{~mL}$ of $0.5 \%$ bupivacaine hydrochloride plus $0.5 \mathrm{mg}(0.5$ $\mathrm{mL}$ ) butorphanol tartrate (Group II, $\mathrm{n}=30$ ). The dose of $0.5 \%$ bupivacaine hydrochloride was calculated according to height of the patient (i.e. $150-160 \mathrm{~cm}: 15 \mathrm{~mL}$ and $161 \mathrm{~cm}$ onwards: $20 \mathrm{~mL}$ ). The total volume of the drug injected in the epidural space was decided according to the height of the patient as follows: Those having height less than $160 \mathrm{cms}$ : Group I ( $15 \mathrm{~mL} 0.5 \%$ bupivacaine plus $0.5 \mathrm{~mL}$ normal saline; total = $15.5 \mathrm{~mL}$ ); Group II (15 mL 0.5\% bupivacaine plus 0.5 $\mathrm{mL}$ butorphanol tartrate; total $=15.5 \mathrm{~mL}$ ). Those greater than $160 \mathrm{cms}$ in height: Group I $(20 \mathrm{~mL} 0.5 \%$ bupivacaine plus 0.5 $\mathrm{mL}$ Normal saline; total $=20.5 \mathrm{ml})$; Group II $(20 \mathrm{~mL} 0.5 \%$ bupivacaine plus $0.5 \mathrm{~mL}$ butorphanol tartrate; total $=20.5$ $\mathrm{mL})$.

\section{Anaesthetic Procedure}

All patients had an intravenous line with 18-G cannula before arriving in the operating room. Anaesthetic machine, breathing circuits and monitors were properly checked beforehand. Full range of drug and equipment including appropriate size laryngoscope blade, endotracheal tubes and airways were kept in hand. After arrival of patients in the operation theatre a baseline pulse rate, blood pressure, ECG, respiratory rate, $\mathrm{SpO}_{2}$ were noted. All patients were preloaded with $15 \mathrm{~mL} / \mathrm{kg}$ of Ringer's lactate solution over 15 minutes before administering epidural block. An epidural anaesthesia tray was kept ready beforehand. Drugs of the same pharmaceutical brand for the study drugs were used in all patients. The drugs were prepared by an anaesthesiologist who was not involved in the study and the epidural anaesthesia was administered by the same anaesthesiologist in all the patients to minimise any operational bias.

The patients were kept in sitting position. The overlying skin was prepared with spirit- povidone iodine -spirit, followed by antiseptic draping. After proper identification of space, $2 \mathrm{~mL}$ of Inj. lignocaine $2 \%$ with adrenaline was used to infiltrate the skin and subcutaneous tissue at L2-3 or L3-4 interspace. For epidural anaesthesia, 18-G Tuohy needle was used. Epidural space was identified by loss of resistance to air technique. After negative aspiration test for blood and CSF, a test dose was administered with $3 \mathrm{~mL}$ of Inj. Lignocaine hydrochloride $2 \%$ with adrenaline and monitoring was done to note any haemodynamic changes indicative of intravascular injection. After ensuring proper epidural placement of the needle tip, the study drug was slowly injected in small increments with repeated aspiration test as per protocol. After placement of study drug, epidural needle was removed; the puncture site was sealed with antiseptic dressing. Monitoring of vital signs was continued throughout the procedure. The patients were made supine. No other analgesic was given to the patients in the intraoperative period. The patients were administered $\mathrm{O}_{2}$, @ $3 \mathrm{~L} / \mathrm{min}$ through face mask. The surgery was allowed after 20 minutes of epidural injection. 
The following parameters were noted: Onset of sensory and motor block, duration of sensory and motor block, height of sensory block and haemodynamic parameters such as Systolic Blood Pressure (SBP), Diastolic Blood Pressure (DBP), Heart Rate (HR) and Respiratory Rate at pre-defined time points. The duration of analgesia and the number of rescue analgesic doses required in first 24 hours were also noted. Adverse events, if any, were also noted.

Sensory block was assessed by pin-prick method every 3 minutes. Onset of sensory block was defined as the time duration (in minute) needed from injection of local anaesthetic solution to the start of loss of pain sensation to pinprick. Sensory block was assessed every 15 minutes postoperatively by pin-prick method. The duration of sensory block was defined as the time duration (in minute) calculated from the onset of sensory block to regression of dermatome by two segments. To determine the duration of analgesia, patients were assessed every 15 minutes postoperatively using a four-point Verbal Rating Scale (VRS) to record observer's measurement of pain. The scores were defined as follows: 1 , comfortable (no pain); 2 , mild pain (elicited only by close questioning); 3 , moderate pain (bothering the patients but often controlled by lying still, analgesic accepted gladly); 4, severe pain (dominating consciousness and calling out for urgent relief). Pain was also assessed at the time of patient's request for analgesia using 11-point $(0-10)$ Visual Analogue Scale (VAS)- essentially a numeric pain scale where 0 - no pain and 10 - the worst pain possible. Duration of analgesia was defined as the time duration (in minutes) from the onset of sensory block to the first request for rescue analgesic (i.e. pain score 3 or more). Rescue analgesic injection diclofenac sodium $1.5 \mathrm{mg} / \mathrm{kg}$ was given intramuscularly. The number of rescue analgesics in 24 hours from administration of epidural anaesthesia was also noted.

Height of block was assessed by pin-prick method over dermatomal segments. Motor block was assessed every 3 minutes by modified Bromage scale as follows: 0- no paralysis, 1-inability to raise extended leg, 2-inability to flex knee and 3-inability to flex ankle and first toe. The time for onset of motor block (minute) was calculated from the time of injection of local anaesthetic solution to achieve motor scale 2 or more. The duration of motor block was assessed using modified Bromage scale every 15 minutes postoperatively. The duration of motor block (in minutes) was calculated from onset of motor block to regaining of full motor power and joint movement. Hypotension was defined as any reduction of blood pressure $<20 \%$ of baseline.

Haemodynamic parameters such as heart rate, Systolic Blood Pressure (SBP), Diastolic Blood Pressure (DBP) and Respiratory Rate were noted at 0, 15, 30, 60, 75, 90, 120 and
Adverse events such as nausea, vomiting, pruritus, hypotension, respiratory depression, shivering, urinary retention, headache, etc., if any were noted.

\section{Statistics}

Sample size calculation was done by taking duration of analgesia as primary outcome variable of interest. It was estimated that 29 subjects will be required per group in order to detect for difference of 45 minutes in this parameter with $80 \%$ power and $5 \%$ probability of type-I error. This calculation assumed a standard deviation of 60 minutes in duration of effective analgesia. Recruitment target was 30 subjects per group in anticipation of any dropout during the study period. For statistical analysis, raw data entered into a Microsoft Excel spreadsheet and analysed by Statistica version 6.0 (Tulsa, Oklahoma: Stat Soft Inc., 2001).

Data was summarised by descriptive statistics, key proportions being expressed along with 95\% confidence interval. Numerical parameters was compared between groups by Student's unpaired ' $\mathrm{t}$ ' test if normally distributed and by Mann-Whitney ' $U$ ' test if otherwise. Categorical variables were compared between groups by Chi-square test or Fisher's exact test as appropriate. All analysis was based on a two-tailed assumption. $P$ value $<0.05$ was considered statistically significant.

\section{RESULTS AND ANALYSIS}

The study spanned from April 2009 to March 2010. Data from all the sixty patients were available. The groups were comparable with respect to the demographic characteristics and the duration of surgery (Table 1).

\begin{tabular}{|c|c|c|c|}
\hline Parameters & $\begin{array}{c}\text { Group I } \\
(\mathbf{n = 3 0 )}\end{array}$ & $\begin{array}{c}\text { Group II } \\
(\mathbf{n = 3 0})\end{array}$ & P value \\
\hline Age (years) & $\begin{array}{c}41.80 \pm 7.83 \\
(27-53)\end{array}$ & $\begin{array}{c}42.47 \pm 6.77 \\
(27-52)\end{array}$ & 0.725 \\
\hline Weight (in kg) & $\begin{array}{c}58.83 \pm 8.65 \\
(45-70)\end{array}$ & $\begin{array}{c}57.40 \pm 9.17 \\
(44-70)\end{array}$ & 0.536 \\
\hline Height (in cm) & $\begin{array}{c}151.40 \pm 5.56 \\
(140-160)\end{array}$ & $\begin{array}{c}150.97 \pm 6.59 \\
(141-162)\end{array}$ & 0.784 \\
\hline $\begin{array}{c}\text { Duration of } \\
\text { Surgery } \\
\text { (in minutes) }\end{array}$ & $\begin{array}{c}97.27 \pm 17.78 \\
(56-120)\end{array}$ & $\begin{array}{c}97.10 \pm 19.59 \\
(55-130)\end{array}$ & 0.973 \\
\hline
\end{tabular}

Data presented as mean \pm standard deviation, range within parenthesis, data analysed using independent sample ' $t$ ' test (Student's unpaired test). Group I, patients receiving epidural bupivacaine alone; Group II, patients receiving butorphanol as additive to epidural bupivacaine.

Table 1. Demographic Parameters

\begin{tabular}{|c|c|c|c|}
\hline Parameters & Group I (n = 30) & Group II (n = 30) & P value \\
\hline Onset of sensory block & $13.73 \pm 2.12(10-8)$ & $14.27 \pm 2.26(10-19)$ & 0.349 \\
\hline Onset of motor block & $22.93 \pm 2.20(20-27)$ & $22.33 \pm 2.22(19-27)$ & 0.296 \\
\hline Duration of sensory block & $230.33 \pm 24.60(185-280)$ & $229.67 \pm 19.78(190-260)$ & 0.908 \\
\hline Duration of motor block & $202.17 \pm 16.01(170-235)$ & $203.20 \pm 14.75(170-230)$ & 0.796 \\
\hline Duration of analgesia & $296.10 \pm 22.95(220-335)$ & $347.20 \pm 18.73(315-390)$ & 0.000 \\
\hline *Block height level T5/T6/T7 & $7 / 16 / 7$ & $8 / 14 / 8$ & 0.875 \\
\hline $\begin{array}{c}\text { Data presented as mean } \pm \text { standard deviation, range within parenthesis, data analysed using independent sample 't' test } \\
\text { (Student's unpaired test), except marked *, which is categorical data and tested with Chi-square test. Group I, patients } \\
\text { receiving epidural bupivacaine alone; Group II, patients receiving butorphanol as additive to epidural bupivacaine. }\end{array}$ \\
\hline \multicolumn{4}{|r|}{ Table 2. Block Characteristics } \\
\hline
\end{tabular}


The times for onset of sensory and motor blocks were comparable in the two groups. Also, the durations of sensory and motor blocks were comparable in the two groups. The distribution of block height level was also comparable between the two groups. However, the duration of analgesia was far prolonged in patients receiving butorphanol as additive to epidural bupivacaine (Table 2 ).

\begin{tabular}{|c|c|c|c|}
\hline Parameters & Group I (n = 30) & Group II (n = 30) & P value \\
\hline VAS scores & $5.13 \pm 0.78(4-6)$ & $5.07 \pm 0.83(4-6)$ & 0.749 \\
\hline VRS scores & $3.43 \pm 0.50(3-4)$ & $3.27 \pm 0.45(3-4)$ & 0.182 \\
\hline $\begin{array}{l}\text { Number of } \\
\text { rescue doses }\end{array}$ & $2.7 \pm 0.79(1-4)$ & $1.5 \pm 0.73(1-3)$ & 0.000 \\
\hline $\begin{array}{l}\text { Data presented as mean } \pm \text { standard deviation, range within } \\
\text { parenthesis, data analysed using independent sample 't' test } \\
\text { (Student's unpaired test). Group I, patients receiving } \\
\text { epidural bupivacaine alone; Group II, patients receiving } \\
\text { butorphanol as additive to epidural bupivacaine. }\end{array}$ \\
\hline \multicolumn{4}{|c|}{ Table 3. Pain Control Status } \\
\hline
\end{tabular}

The pain control status as measured using VAS or VRS scores at the time of request for analgesics were comparable between the groups. However, significantly less number of rescue analgesics $(P=0.000)$ received by the patients who were receiving butorphanol epidurally as adjuvant. While the bupivacaine alone group required an average of 2.7 doses of rescue analgesics, the study group (receiving butorphanol additive) needed only 1.5 doses in the first 24 hours of administration of epidural anaesthesia. This is highly significant on analysis $(P=0.000)$ (Table 3$)$.

\begin{tabular}{|c|c|c|c|}
\hline Parameters & $\begin{array}{c}\text { Group I } \\
(\mathbf{n = 3 0 )}\end{array}$ & $\begin{array}{c}\text { Group II } \\
(\mathbf{n = 3 0 )}\end{array}$ & $\boldsymbol{P}$ value \\
\hline 0 Min & $80.87 \pm 6.82$ & $81.40 \pm 5.89$ & 0.747 \\
\hline 15 Mins & $80.20 \pm 5.97$ & $82.07 \pm 4.50$ & 0.177 \\
\hline 30 Mins & $74.00 \pm 4.93$ & $75.93 \pm 3.58$ & 0.088 \\
\hline 60 Mins & $69.07 \pm 4.57$ & $70.50 \pm 3.45$ & 0.176 \\
\hline 75 Mins & $70.53 \pm 3.79$ & $69.93 \pm 3.91$ & 0.549 \\
\hline 90 Mins & $72.00 \pm 4.03$ & $72.53 \pm 3.52$ & 0.587 \\
\hline 120 Mins & $72.60 \pm 4.55$ & $73.37 \pm 3.42$ & 0.464 \\
\hline 240 Mins & $76.00 \pm 3.96$ & $76.17 \pm 3.00$ & 0.855 \\
\hline
\end{tabular}

Data presented as mean \pm standard deviation, range within parenthesis, data analysed using independent sample ' $t$ ' test (Student's unpaired test). Group I, patients receiving epidural bupivacaine alone; Group II, patients receiving butorphanol as additive to epidural bupivacaine. Mins, minutes.

Table 4. Heart Rates at Different Points of Time

\begin{tabular}{|c|c|c|c|}
\hline Parameters & $\begin{array}{l}\text { Group I } \\
(n=30)\end{array}$ & $\begin{array}{l}\text { Group II } \\
(n=30)\end{array}$ & $P$ value \\
\hline $0 \mathrm{Min}$ & $124.67 \pm 6.92$ & $124.33 \pm 7.18$ & 0.855 \\
\hline 15 Mins & $124.73 \pm 7.83$ & 125.1 & \\
\hline $30 \mathrm{~N}$ & \pm 5.11 & 110.6 & \\
\hline 60 Mins & $107.40 \pm 5.46$ & $107.47 \pm 5.70$ & .963 \\
\hline 75 Mins & $112.33 \pm 5.15$ & $111.53 \pm 5.32$ & \\
\hline 90 Mins & $116.40 \pm 4.25$ & $116.13 \pm 4.61$ & 0.817 \\
\hline 120 Mins & $121.73 \pm 5.94$ & $122.73 \pm 5.57$ & 0.504 \\
\hline 240 Mins & $123.93 \pm 3.54$ & $122.67 \pm 3.50$ & 0.169 \\
\hline \multicolumn{4}{|c|}{$\begin{array}{l}\text { Data presented as mean } \pm \text { standard deviation, range within } \\
\text { parenthesis, data analysed using independent sample 't' tes } \\
\text { (Student's unpaired test). Group I, patients receiving } \\
\text { epidural bupivacaine alone; Group II, patients receiving } \\
\text { butorphanol as additive to epidural bupivacaine. Mins } \\
\text { minutes. }\end{array}$} \\
\hline \multicolumn{4}{|c|}{$\begin{array}{c}\text { Table 5. Systolic Blood Pressure (SBP) at } \\
\text { Different Points of Time }\end{array}$} \\
\hline
\end{tabular}

\begin{tabular}{|c|c|c|c|}
\hline Parameters & $\begin{array}{l}\text { Group I } \\
(n=30)\end{array}$ & $\begin{array}{l}\text { Group II } \\
(n=30)\end{array}$ & $P$ value \\
\hline $0 \mathrm{Min}$ & $77.40 \pm 5.90$ & $77.73 \pm 5.75$ & 0.825 \\
\hline 15 Mins & $75.13 \pm 6.57$ & $74.13 \pm 6.73$ & 0.563 \\
\hline 30 Mins & $66.87 \pm 5.48$ & $66.27 \pm 5.11$ & 0.663 \\
\hline 60 Mins & $65.53 \pm 3.55$ & $65.67 \pm 4.33$ & 0.897 \\
\hline 75 Mins & $69.53 \pm 2.96$ & $70.07 \pm 3.54$ & 0.529 \\
\hline 90 Mins & $72.67 \pm 2.80$ & $73.03 \pm 3.64$ & 0.664 \\
\hline 120 Mins & $76.27 \pm 4.09$ & $74.47 \pm 4.54$ & 0.112 \\
\hline 240 Mins & $78.60 \pm 3.87$ & $77.47 \pm 5.06$ & 0.334 \\
\hline \multicolumn{4}{|c|}{$\begin{array}{l}\text { Data presented as mean } \pm \text { standard deviation, range within } \\
\text { parenthesis, data analysed using independent sample ' } t \text { ' test } \\
\text { (Student's unpaired test). Group I, patients receiving epidura } \\
\text { bupivacaine alone; Group II, patients receiving butorphanol as } \\
\text { additive to epidural bupivacaine. Mins, minutes. }\end{array}$} \\
\hline \multicolumn{4}{|c|}{$\begin{array}{c}\text { Table 6. Diastolic Blood Pressure at } \\
\text { different Points of Time }\end{array}$} \\
\hline
\end{tabular}

\begin{tabular}{|c|c|c|c|}
\hline Parameters & $\begin{array}{c}\text { Group I } \\
(\mathbf{n}=\mathbf{3 0})\end{array}$ & $\begin{array}{c}\text { Group II } \\
(\mathbf{n}=\mathbf{3 0})\end{array}$ & P value \\
\hline 0 Min & $16.56 \pm 2.06$ & $16.60 \pm 2.18$ & 0.952 \\
\hline 15 Mins & $16.93 \pm 2.02$ & $16.80 \pm 2.50$ & 0.821 \\
\hline 30 Mins & $16.53 \pm 2.73$ & $17.07 \pm 1.80$ & 0.375 \\
\hline 60 Mins & $16.73 \pm 2.07$ & $17.07 \pm 1.72$ & 0.500 \\
\hline 75 Mins & $17.13 \pm 1.87$ & $17.33 \pm 1.92$ & 0.684 \\
\hline 90 Mins & $17.53 \pm 1.63$ & $17.27 \pm 2.07$ & 0.582 \\
\hline 120 Mins & $17.07 \pm 1.94$ & $17.40 \pm 2.04$ & 0.520 \\
\hline 240 Mins & $16.60 \pm 1.83$ & $17.00 \pm 2.08$ & 0.433 \\
\hline
\end{tabular}

Data presented as mean \pm standard deviation, range within parenthesis, data analysed using independent sample ' $t$ ' test (Student's unpaired test). Group I, patients receiving epidural bupivacaine alone; Group II, patients receiving butorphanol as additive to epidural bupivacaine.

\section{Table 7. Respiratory Rate at Different Points of Time}

The haemodynamic parameters such as HR, SBP, DBP and respiratory parameter (respiratory rate) were comparable between the groups at different points of time from administration of epidural anaesthesia (in the intraoperative and postoperative period). There was decreasing trend in heart rate, systolic and diastolic blood pressure in both the groups initially during intraoperative period. But these falls were within normal range on clinical ground (Table 4 to 7).

\begin{tabular}{|c|c|c|c|}
\hline Parameters & $\begin{array}{l}\text { Group I } \\
(n=30)\end{array}$ & $\begin{array}{l}\text { Group II } \\
(n=30)\end{array}$ & $P$ value \\
\hline $\begin{array}{l}\text { Urinary } \\
\text { retention }\end{array}$ & 2 & 1 & \multirow{6}{*}{0.646} \\
\hline Nausea & 2 & 2 & \\
\hline Vomiting & 1 & 1 & \\
\hline $\begin{array}{l}\text { Nausea and } \\
\text { vomiting }\end{array}$ & 2 & 3 & \\
\hline Pruritus & 2 & 2 & \\
\hline Sedation & 1 & 2 & \\
\hline \multicolumn{4}{|c|}{$\begin{array}{l}\text { Categorical data and tested with Chi-square test. Group I, } \\
\text { patients receiving epidural bupivacaine alone; Group II, } \\
\text { patients receiving butorphanol as additive to epidural } \\
\text { bupivacaine. }\end{array}$} \\
\hline \multicolumn{4}{|c|}{ Table 8. Adverse Events } \\
\hline
\end{tabular}

\section{DISCUSSION}

Although ropivacaine and levobupivacaine have gained much popularity as local anaesthetic agents for epidural anaesthesia, bupivacaine is still commonly being used in developing countries like ours owing to the latter's easy 
availability and low cost. Since the introduction of epidural opioids into clinical practice of anaesthesia in 1979, it has gained widespread popularity and acceptance. ${ }^{8}$ The advantage of epidural opioids is the synergistic effect with local anaesthetics, allowing a marked decrease in the dose of both the drugs to achieve the same level of analgesia. ${ }^{9-13}$

The present study was designed to compare between low dose $(0.5 \mathrm{mg})$ butorphanol as adjuvant to epidural bupivacaine $(0.5 \%)$ and epidural bupivacaine $(0.5 \%)$ alone for perioperative analgesia in elective gynaecological surgeries. The use of combination of bupivacaine and butorphanol in epidural route is not new and has already been reported in different studies ${ }^{7,14-17}$ with variable modification of block characteristics.

The present study finds that the addition of low-dose $(0.5$ $\mathrm{mg}$ ) butorphanol to epidural bupivacaine $(0.5 \%)$ prolongs the duration of analgesia up to $347.20 \pm 18.73$ minutes compared with $296.10 \pm 22.95$ minutes with epidural bupivacaine $(0.5 \%)$ alone. The total consumption of rescue analgesic was also less (1.5 doses/24 hrs.) in the combination group compared to control group ( 2.7 doses/ 24 hrs.). There was no significant change in onset and duration of sensory and motor block. The prolongation of duration of analgesia is in agreement with that observed by Hunt $\mathrm{C} O$ et $a l,{ }^{14}$ who had observed that the mean duration of pain relief was approximately $67 \pm 15$ minutes more in patients receiving butorphanol as epidural additive compared with bupivacaine $(0.25 \%)$ alone. Abboud $\mathrm{M}$ et al ${ }^{18}$ compared $5 \mathrm{mg}$ morphine with $4 \mathrm{mg}, 2 \mathrm{mg}$ and $1 \mathrm{mg}$ butorphanol, all as epidural regimen for postoperative pain control in women undergoing caesarean delivery. Epidural morphine provided satisfactory analgesia with slow onset and prolonged duration of approximately $21 \mathrm{hrs}$. Epidural butorphanol achieved analgesia of rapid onset and increasing duration. The effectiveness was observed with increasing dose; approximately $8 \mathrm{hrs}$. when using $4 \mathrm{mg}$. Addition of 1 or $2 \mathrm{mg}$ butorphanol to epidural bupivacaine $(0.25 \%)$ achieved longer duration of labour analgesia $(139 \pm 11$ mins and $141 \pm$ 14 mins, respectively) compared with bupivacaine alone (96 \pm 6 mins). Sixty-two percent of the patients who received morphine had pruritus and somnolence was the main adverse event encountered in patients who received epidural butorphanol. The ventilatory response to $\mathrm{CO} 2$ was found depressed with the use of morphine and after 2 and $4 \mathrm{mg}$ dose of butorphanol, but the duration of depression was more prolonged after morphine. The authors concluded that epidural butorphanol is effective in providing pain relief after caesarean section with minor side effects. However, in the present study comparatively more prolongation of analgesia was observed with low-dose of butorphanol. Various studies using epidural butorphanol for postoperative analgesia have reported the duration of analgesia to be $4-6 \mathrm{~h}, 5 \mathrm{~h}$ and $5.35 \mathrm{~h}$ with $0.5 \mathrm{mg}, 1 \mathrm{mg}$ and $2 \mathrm{mg}$, respectively. ${ }^{18-20}$ Venkatraman $\mathrm{R}$ and Sandhiya $\mathrm{R}^{21}$ also reported that $2 \mathrm{mg}$ epidural butorphanol provides analgesia for 6 - 9 hours. This longer duration of analgesia could be due to increase in potentiality of local anaesthetics by opioid, direct action on opioid receptor or because of systemic absorption of opioid.12,13,22

Although the duration of analgesia was found to be prolonged, the onset and duration of sensory and motor blockade was found comparable between the two groups in the present study. The use of lower doses of butorphanol $(0.5$ $\mathrm{mg}$ and $0.75 \mathrm{mg}$ ) with epidural bupivacaine for postoperative analgesia following caesarean delivery has been reported in the literature. ${ }^{7}$

In a dose-response study ${ }^{14}$ of a combination of $0.25 \%$ bupivacaine combined with $0,1,2$ or $3 \mathrm{mg}$ of butorphanol was studied in 40 labouring parturients. The optimal dose of butorphanol combined with 8.5 to $10 \mathrm{~mL} 0.25 \%$ bupivacaine was $2 \mathrm{mg}$. They observed that with $2 \mathrm{mg}$, the duration of analgesia was significantly greater and the time to onset of analgesia was significantly shorter than when no butorphanol was added, and the amount of bupivacaine could be reduced $50 \%$. Adverse foetal effects were not observed except that of a low amplitude sinusoidal foetal heart rate pattern with doses of $3 \mathrm{mg}$ butorphanol. Palacios $\mathrm{Q} \mathrm{T}$ et al ${ }^{23}$ compared doses of 1,2 and $4 \mathrm{mg}$ of epidural butorphanol with $5 \mathrm{mg}$ of epidural morphine for post-caesarean section analgesia in term parturients. Epidural butorphanol provided 3 to 4 hours of effective analgesia with significantly lower frequency of pruritus than morphine. Adequacy of analgesia was indistinguishable between morphine and butorphanol. Kar P24 used $1 \mathrm{mg}, 2 \mathrm{mg}$ and $4 \mathrm{mg}$ butorphanol epidurally and found that addition of 2 and $4 \mathrm{mg}$ of butorphanol significantly quickens the onset of sensory block compared with $1 \mathrm{mg}$ butorphanol additive group and bupivacaine alone group. Mean difference of about 3 mins was observed between the first and last two groups. They concluded that butorphanol have strong analgesic activity without fear of respiratory depression and can be used as a safe and effective adjuvant in a dose of $2 \mathrm{mg}$ and $4 \mathrm{mg}$. Hence, it appears that the low-dose $(0.5 \mathrm{mg})$ used in the present study fails to modify other block characteristics except prolongation of duration of analgesia. However, further study with low and higher doses involving a larger population sample is warranted to draw a concrete conclusion regarding this.

Chaithanya $\mathrm{K}$ et al 25 found early onset of analgesia (2.69 \pm 0.59 vs $5.27 \pm 1.06 \mathrm{mins}$ ) and longer duration of analgesia ( $6.98 \pm 0.52$ vs $2.98 \pm 0.46$ hours) with the use of butorphanol as additive to epidural bupivacaine compared with bupivacaine alone. Yogeswaran $\mathrm{Y}$, et $\mathrm{al}^{26}$ concluded that butorphanol $4 \mathrm{mg}$ with epidural bupivacaine achieves faster onset of sensory blockade (18.33 vs 25.67 mins), faster onset of motor block (9.33 vs 15.17 mins) and longer duration of analgesia (151.67 vs 101.33 mins) without any major side effects, except significant sedation as compared with bupivacaine alone.

Butorphanol (2 $\mathrm{mg}$ ) was reported to achieve better quality of pain relief (lower VAS scores) and less nauseavomiting and slightly more sedation compared with tramadol (100 mg). Although, both butorphanol (2 mg) and tramadol (100 mg) as epidural adjuvant were effective for prolonging postoperative analgesia, a shorter duration of analgesia was noticed with butorphanol compared with tramadol; $5.35 \pm$ 0.29 versus $6.25 \pm 0.1 .58$ hours, respectively. ${ }^{20}$ In another study, ${ }^{27}$ shorter duration of analgesia and sedation was recognised as major disadvantage with butorphanol when compared with tramadol. The authors ${ }^{27}$ commented that epidural tramadol with systemic antiemetic support is better than epidural butorphanol for the former's advantage of longer duration of analgesia, especially in ambulatory surgery settings, elderly and obese patients.

In a recent study, Kaur J and Bajwa S S28 concluded that butorphanol and fentanyl as epidural additive significantly 
quickens the onset and completion of analgesia and provide more effective and longer duration of analgesia as compared with bupivacaine alone for lower abdominal surgeries. A comparable stable haemodynamics and absence of serious cardiorespiratory adverse effects were reported in that study. The authors concluded butorphanol provides significantly prolonged postoperative analgesia compared with fentanyl additive group or bupivacaine alone group. They further stated that butorphanol and fentanyl are equally safe. In a previous study, Malik $\mathrm{P}$ et $\mathrm{al}^{29}$ also report that butorphanol provides a longer duration of analgesia, but more sedation compared with fentanyl while increased incidence of nausea and pruritus is associated with the use of the latter. Devulapalli $\mathrm{P} K$, et $\mathrm{al}^{30}$ recently reported that epidural butorphanol has faster onset of action compared with epidural morphine (14.66 vs 34.76 mins, respectively).

In the present study, a comparable block heights was achieved in patients receiving butorphanol additive with epidural bupivacaine. This indicates that the local anaesthetic domain of bupivacaine is not modified by butorphanol. The present study finds no case of hypotension and no significant difference in SBP and HR between the two groups. This finding is in agreement with the observations of Hunt $\mathrm{C} O$, et al. ${ }^{14}$ The stable haemodynamics may be attributed to gradual fall of blood pressure in epidural block owing to slow spread of block and thereby allowing more time for compensation to occur. No significant difference in respiratory rate was observed between the two groups in the present study. This finding corroborates with the observations of Abboud T K, et $\mathrm{al}^{18}$ who had observed that there was no significant respiratory depression following epidural administration of 1 mg of butorphanol by monitoring the carbon dioxide response curve and respiratory rate. In the present study, the differences in the incidences of adverse events were not significant. High lipid solubility and high affinity for opioid receptors leads to efficient diffusion of drug in the substance of local segments of spinal cord. ${ }^{27}$ This limits the amount of drug available in the cerebrospinal fluid for transport to the brain stem to produce adverse events. The use of low-dose also attributes to reduced adverse events. These findings were in agreement with most of the studies using comparatively higher doses $(2 \mathrm{mg}) .14,24$

Limitations of the present study are that it was not designed as a dose-response study to find out the effect of higher doses of butorphanol on block characteristics and to find out any change in the incidences of adverse events of such different doses if any. Sedation was not observed using any objective methods such as Bispectral Index (BIS) Score or common clinical tools such as Ramsay Sedation Scale or Observer Assessment of Alertness/Sedation (OAA/S) scale score.

In summary, the present study observes that addition of low-dose $(0.5 \mathrm{mg})$ butorphanol to epidural bupivacaine $(0.5 \%)$ significantly prolongs the duration of analgesia, thereby reducing total consumption of rescue analgesics without modifying the onset and duration of sensory and motor block and with comparable haemodynamic parameters and acceptable adverse event profile compared with bupivacaine alone.

\section{CONCLUSION}

The present study concludes that addition of single low-dose $(0.5 \mathrm{mg})$ of butorphanol with epidural bupivacaine $(0.5 \%)$ significantly prolongs the duration of effective postoperative analgesia without modifying the onset and duration of sensory and motor block. The use of butorphanol leads to less consumption of rescue analgesics. Comparable haemodynamic parameters and acceptable adverse event profile were observed in both the groups.

\section{REFERENCES}

[1] Bonica JJ. The need of a taxonomy. Pain 1979;6(3):247-8.

[2] Yeager MP, Glass DD, Neff RK, et al. Epidural anesthesia and analgesia in high-risk surgical patients. Anesthesiology 1987;66(6):729-36.

[3] Singh M. Stress response and anaesthesia: altering the peri and post-operative management. Indian J Anaesth 2003;47(6):427-34.

[4] Haliloglu M, Omur D, Yuksel TC, et al. Post operative effects: anesthesia. J Anesth Clin Res 2012;4:291.

[5] Block BM, Liu SS, Rowlingson AJ, et al. Efficacy of postoperative epidural analgesia: a meta-analysis. JAMA 2003;290(18):2455-63.

[6] Raj APV, Narayanan VS. A comparative study of epidural $0.5 \%$ levobupivacaine versus epidural $0.5 \%$ levobupivacaine with dexmedetomedine analgesia and haemodynamics. Journal of Evolution of Medical and Dental Sciences 2015;4(57):9978-89.

[7] Pokharel K, Rahman TR, Singh SN, et al. The efficacy and safety of low dose epidural butorphanol on postoperative analgesia following cesarean delivery. J Nepal Med Assoc 2008;47(170):57-61.

[8] Behar M, Magora F, Olshwang D, et al. Epidural morphine in treatment of pain. Lancet 1979;313(8115):527-9.

[9] Saldman LJ, Cousins MJ, Mather LE. Intrathecal and epidural administration of opioids. Anesthesiology 1984;61(3):276-310.

[10] Akerman B, Arwestrom E, Post C. Local anesthetics potentiate spinal morphine antinociception. Anesth Analg 1988;67(10):943-8.

[11] Morgan M. The rational use of intrathecal and extradural opioids. Br J Anaesth 1989;63(2):165-88.

[12] Saxena AK, Arava SK. Current concepts in neuraxial administration of opioids and non-opioids: an overview and future perspectives. Indian J Anaesth 2004;48(1):13-24.

[13] Christiansson L. Update on adjuvants in regional anaesthesia. Period Biol 2009;111(2):161-70.

[14] Hunt CO, Naulty JS, Malinow AM, et al. Epidural butorphanol-bupivacaine for analgesia during labor and delivery. Anesth Analg 1989;68(3):323-7.

[15] Rodriguez J, Abboud TK, Reyes A, et al. Continuous infusion epidural anesthesia during labor: a randomized, double-blind comparison of $0.0625 \%$ bupivacaine $/ 0.002 \%$ butorphanol and $0.125 \%$ bupivacaine. Reg Anesth 1990;15(6):300-3. 
[16] Lawhorn CD, Stoner JM, Schmitz ML, et al. Caudal epidural butorphanol plus bupivacaine versus bupivacaine in pediatric outpatient genitourinary procedures. J Clin Anesth 1997;9(2):103-8.

[17] Singh V, Kanaujia A, Singh GP. Efficacy of caudal butorphanol. Indian J Pediatr 2006;73(2):147-50.

[18] Abboud TK, Moore M, Zhu J, et al. Epidural butorphanol or morphine for the relief of postcesarean section pain: ventilatory responses to carbon dioxide. Anesth Analg 1987;66(9):887-93.

[19] Tan PH, Chou AK, Perng JS, et al. Comparison of epidural butorphanol plus clonidine with butorphanol alone for postoperative pain relief. Acta Anaesthesiol Sin 1997;35(2):91-6.

[20] Gupta R, Kaur S, Singh S, et al. A comparison of epidural butorphanol and tramadol for postoperative analgesia using CSEA technique. J Anaesthesiol Clin Pharmacol 2011;27(1):35-8.

[21] Venkatraman R, Sandhiya R. Evaluation of efficacy of epidural butorphanol tartrate for postoperative analgesia. Int J Pharm Pharm Sci 2015;7(2):52-4.

[22] George MJ. The site of action of epidurally administered opioids and its relevance to postoperative pain management. Anaesthesia 2006;61(7):659-64.

[23] Palacios QT, Jones MM, Hawkins JL, et al. Postcaesarean section analgesia: a comparison of epidural butorphanol and morphine. Can J Anaesth 1991;38(1): 24-30.
[24] Kar P. A comparative study between epidural butorphanol with bupivacaine and bupivacaine alone for intra-operative and post-operative analgesia in lower limb orthopaedic surgeries. Int J Res Med Sci 2016;4(10):4251-55.

[25] Chaithanya K, Reddy N, Gandra S, et al. A comparative study of the effect of epidural bupivacaine $(0.125 \%)$ versus epidural bupivacaine $(0.125 \%)$ and butorphanol $(2 \mathrm{mg})$ for post-operative pain relief in lower abdominal and lower limb surgeries. JEMDS 2014;3(35):9243-9.

[26] Yogeshwaran S, Balasubramanian S, Sanmugapiriya K, et al. Effect of butorphanol as an adjuvant in epidural analgesia for inguinal hernia surgery. Int J Sci Stud 2016;4(3):17-20.

[27] Swathi N, Ashwini N, Shukla MI. Comparative study of epidural bupivacaine with butorphanol and bupivacaine with tramadol for postoperative pain relief in abdominal surgeries. Anesth Essays Res 2016;10(3):462-7.

[28] Kaur J, Bajwa SJ. Comparison of epidural butorphanol and fentanyl as adjuvants in the lower abdominal surgery: a randomized clinical study. Saudi J Anaesth 2014;8(2):167-71.

[29] Malik P, Manchanda C, Malhotra N. Comparative evaluation of epidural fentanyl and butorphanol for postoperative analgesia. J Anaesthesiol Clin Pharmacol 2006;22(4):377-82.

[30] Devulapalli PK, Verma HR. A comparative study of epidural butorphanol and epidural morphine for the relief of postoperative pain. JEMDS 2015;4(30):516171. 